\title{
Greenland ice sheet surface mass-balance variability: 1991-2003
}

\author{
J.E. BOX \\ Byrd Polar Research Center, The Ohio State University, 1090 Carmack Road, Columbus, OH 43210-1002, USA \\ E-mail: box.11@osu.edu
}

\begin{abstract}
The Polar MM5 mesoscale atmospheric model was run for 13 years (1991-2003) over Greenland at $24 \mathrm{~km}$ horizontal resolution (Box and others, 2004). The model physics were driven by satellite, station and weather-balloon observational data assimilation, i.e. European Centre for MediumRange Weather Forecasts (ECMWF) operational analysis. The analysis in this study focuses on the response of the surface mass balance to its primary controls: temperature and precipitation. The results indicate coherent spatial patterns of variability and statistically significant links with temperature and precipitation and the North Atlantic Oscillation. Precipitation trends have the same spatial pattern and sign as temperature, suggesting an association of precipitation and temperature variability. Increasing temperatures contribute to an increasing ablation trend and expansion of the ablation zone despite increasing accumulation trends. The Pinatubo (Philippines) volcanic cooling in the early 1990s enhances this apparent warming trend. Only in the northeast does precipitation appear to dominate the surface mass balance, where both temperature and precipitation have decreased. There is little evidence for a total ice-sheet surface mass-balance trend, although the meltwater runoff has a positive trend and, combined with iceberg discharge and basal melting estimates, suggests the ice sheet as a whole is in a state of net mass loss over this period.
\end{abstract}

\section{INTRODUCTION}

Ice-sheet mass-balance fluctuations influence global sealevel and ocean thermohaline circulation changes. However, the state of ice-sheet mass balance remains imprecisely known (Van der Veen, 2002). Greenland ice sheet surface mass-balance components have been resolved by statistical compilations of available observational data (e.g. Ohmura and others, 1999; McConnell and others, 2001). However, these lack either the temporal dimension or complete spatial coverage. Recently, high-resolution limited-area regional climate models (RCMs) have filled this space-time gap over the Greenland ice sheet (e.g. Bromwich and others, 2001a, b; Cassano and others, 2001; Hanna and others, 2002; Box and Rinke, 2003; Box and others, 2004) and have facilitated investigation of spatial and temporal variability of individual surface mass-balance components in a consistent frame. RCMs have thus provided the spatial resolution needed to resolve the ablation zone, spatial closure needed for whole ice-sheet mass-balance assessments, and annually resolved results useful for variability analyses. RCMs are commonly configured to be driven by available satellite, station and weather-balloon observations and can thus be thought of as physically based interpolators used to provide information for regions not benefiting from direct observations.

Automatic weather station (AWS) observations (Steffen and Box, 2001) and glacier survey data (Greuell and others, 2001) have proven vital in assessing RCM skill over the Greenland ice sheet (Box and others, 2004). RCMs have proven to offer accurate representation of temporal variability (Bromwich and others, 2001a; Cassano and others, 2001; Box and Rinke, 2003; Box and others, 2004). However, apparently small systematic biases, particularly in nearsurface vertical temperature and wind-speed gradients and radiation fluxes, can strongly bias modeled melt rates (Box and others, 2004). Although it is unlikely that the propagation of systematic error will ever be eliminated from RCM output, AWS and glacier survey data make possible adjustments of the model output to deliver more reliable, observationally constrained estimates of surface climatology applicable in mass-balance studies. The overall uncertainty of modeled surface mass-balance parameters remains high owing to the fact that available in situ observations are few and were used for model tuning and therefore are unavailable for further testing. Details of the validation of the Polar MM5 RCM over Greenland are found in Bromwich and others (2001a), Cassano and others (2001) and Box and others (2004).

Box and others (2004) demonstrated that summer temperature and annual precipitation variability explain $>90 \%$ of the variance in modeled surface mass-balance totals spanning 1991-2000. Here, the temporal variability in temperature and precipitation is explored further, with a larger dataset spanning 1991-2003, as it pertains to the surface mass-balance variability. First, the absolute magnitude of interannual variability is presented and discussed. Second, trends in temperature, precipitation and surface mass balance over the ice sheet are examined. Temperature and precipitation variability is then analyzed in the context of a dominant regional atmospheric mode of variability, the North Atlantic Oscillation (NAO).

\section{ABSOLUTE VARIABILITY: 1991-2003}

The envelope of interannual variability as measured by the range in values over the period 1991-2003 for each model gridcell illustrates the concentration of temperature variability along the western slope and in particular near the icesheet margin (Fig. 1a). Reasons for this pattern include more variable wind direction along the western slope influenced by the NAO (Li, 2003) and that sea-ice concentration is more variable along the west coast (Cappelen and others 2001). Links with the NAO are explored further toward the end of this paper.

The variability in precipitation exhibits a similar pattern to other mass fluxes, i.e. largest absolute variability is found 


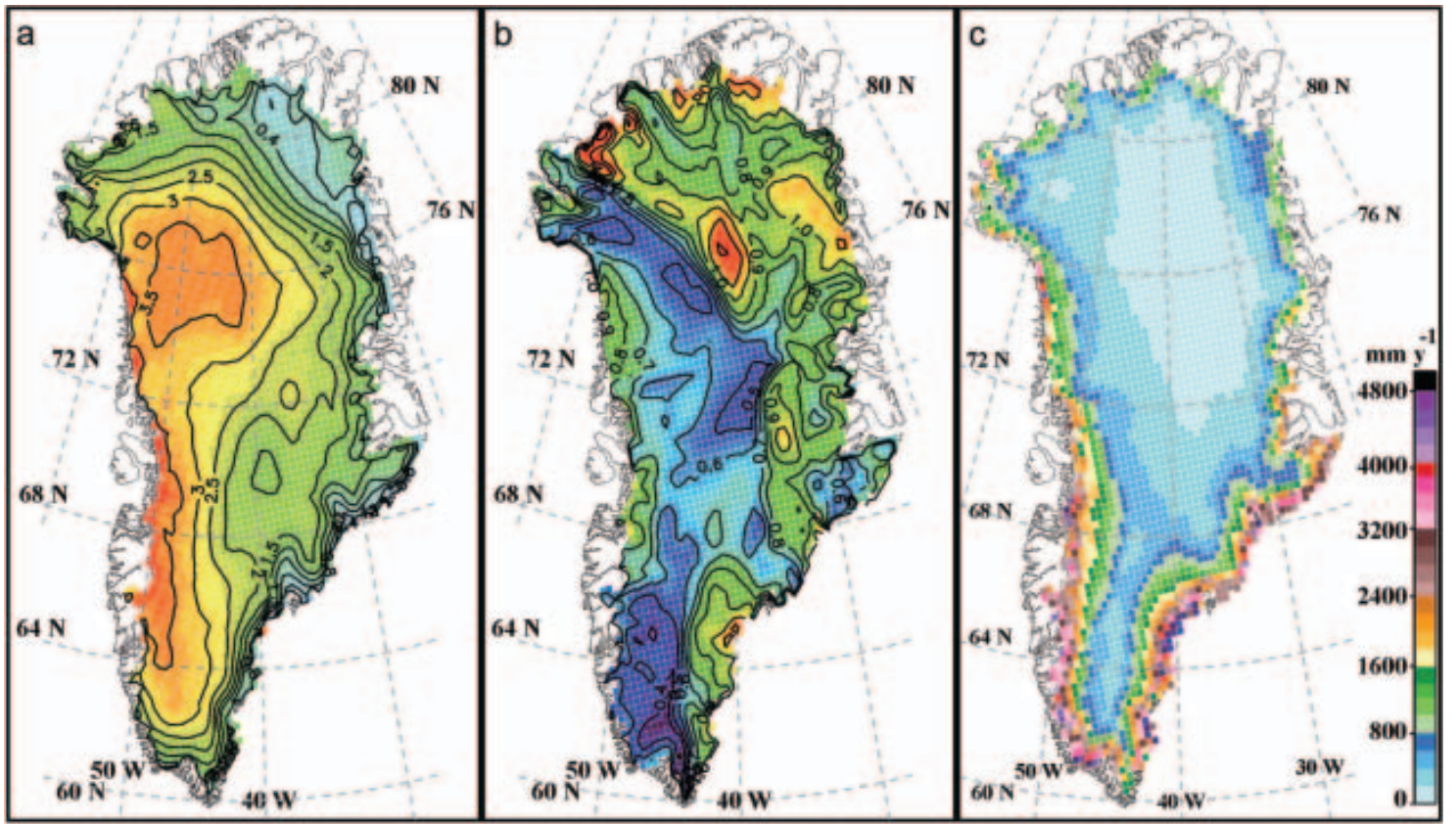

Fig. 1. Range in annual mean temperature (a), annual precipitation (range/mean) (b) and range in surface mass balance (c) in the Polar MM5 regional climate model over 13 years (1991-2003).

where fluxes are largest. The spatial pattern of precipitation normalized by its mean (Fig. 1b) exhibits a different pattern, one that suggests largest relative variability either where fluxes are small, i.e. at higher elevations and in the northeast zone of minimum accumulation, or in the southeast, where transient cyclones deliver precipitation highly variable in magnitude. Extremely large precipitation rates over the southeast spanning 2002 to early 2003 contribute to the variability maximum in the southeast. A belt of relatively low variability is evident extending from the northwest to the south. This pattern reflects relatively consistent precipitation delivered by prevailing westerly flow. Precipitation enhancement along windward slopes leads to a precipitation shadow on leeward slopes, manifesting in a pattern of relatively inconsistent precipitation along the leeward northeast. Over the northeast, on rarer occasions, precipitation arrives from the north and northeast (Li, 2003), further contributing to the relatively large variability there.

Figure 1c illustrates how absolute surface mass-balance variability is greatest (up to $500 \mathrm{~cm}$ w.e.) along the ice-sheet margin. This pattern reflects the envelope of melt and accumulation variations between anomalous years. For example, melting was minimal in 1992 while precipitation was relatively large. In that year, the surface mass balance was $\sim 150 \mathrm{~km}^{3}$ more than the mean of nearly $200 \mathrm{~km}^{3}$. In an opposite extreme, 1998 temperatures were relatively high, and, combined with $\sim 40 \mathrm{~km}^{3}$ below average precipitation and extremely large runoff $\left(\sim 450 \mathrm{~km}^{3}\right)$, the total ice-sheet surface mass balance may even have been negative for that year, not including the losses from iceberg discharge and basal melting.

\section{TRENDS}

Trends in temperature, precipitation and surface mass balance are apparent in the 1991-2003 Polar MM5 results. Seasonally, widespread temperature increases are evident except in parts of the north and northeast ice sheet. Some of this apparent warming can be attributed to Pinatubo (Philippines) volcanic cooling evident over Greenland (Abdalati and Steffen, 1997; Box, 2002) in the early part of this analysis, i.e. 1992. Maximum warming was concentrated near the ice margin, where up to $3.0 \mathrm{~K}$ warming is evident in the ablation season, here defined roughly as MaySeptember (Fig. 2a). An average increase in melt duration of up to 1.7 weeks over these 13 years is evident in southeastern Greenland, as annual temperatures there have increased by $>3 \mathrm{~K}$ since the early 1990 s. Annual temperature changes were positive across the ice sheet, $1.76 \mathrm{~K}$ on average, and up to $6.8 \mathrm{~K}$ near the location of the melt-season temperature trend maximum.

Overall trends in precipitation for the ice sheet were also positive (Fig. 2b). The southeastern maximum is influenced by a persistent and large positive anomaly, lasting from September 2002 to April 2003. However, the positive trend remains when 2002 and 2003 are excluded, implying that increasing accumulation in the southeast is part of a larger trend. Annual modeled precipitation (1991-2001) has a notable correlation $(r>0.7)$ with station records in southeast and western Greenland (data from Cappelen, 2003). Precipitation changes were negative and relatively small along the east and northeast, coinciding with decreasing temperatures, and still perhaps significant to regional mass balance owing to lesser accumulation rates.

The combined effect of temperature and precipitation trends over this period is of increased ablation and increased accumulation. The net effect of these competing factors suggests that the temperature increases have dominated the surface mass-balance change in the ablation zone (Fig. 2c). Adjacent to the ablation zone, an acute increase in net accumulation is simulated. This pattern of a steepening elevation profile of net balance has been observed over many glaciers in the Northern Hemisphere (Dyurgerov and Dwyer, 2001). These results are in line with results of future scenarios by Wild and others (2003), whereby increases in precipitation offset the negative mass-balance tendencies of 


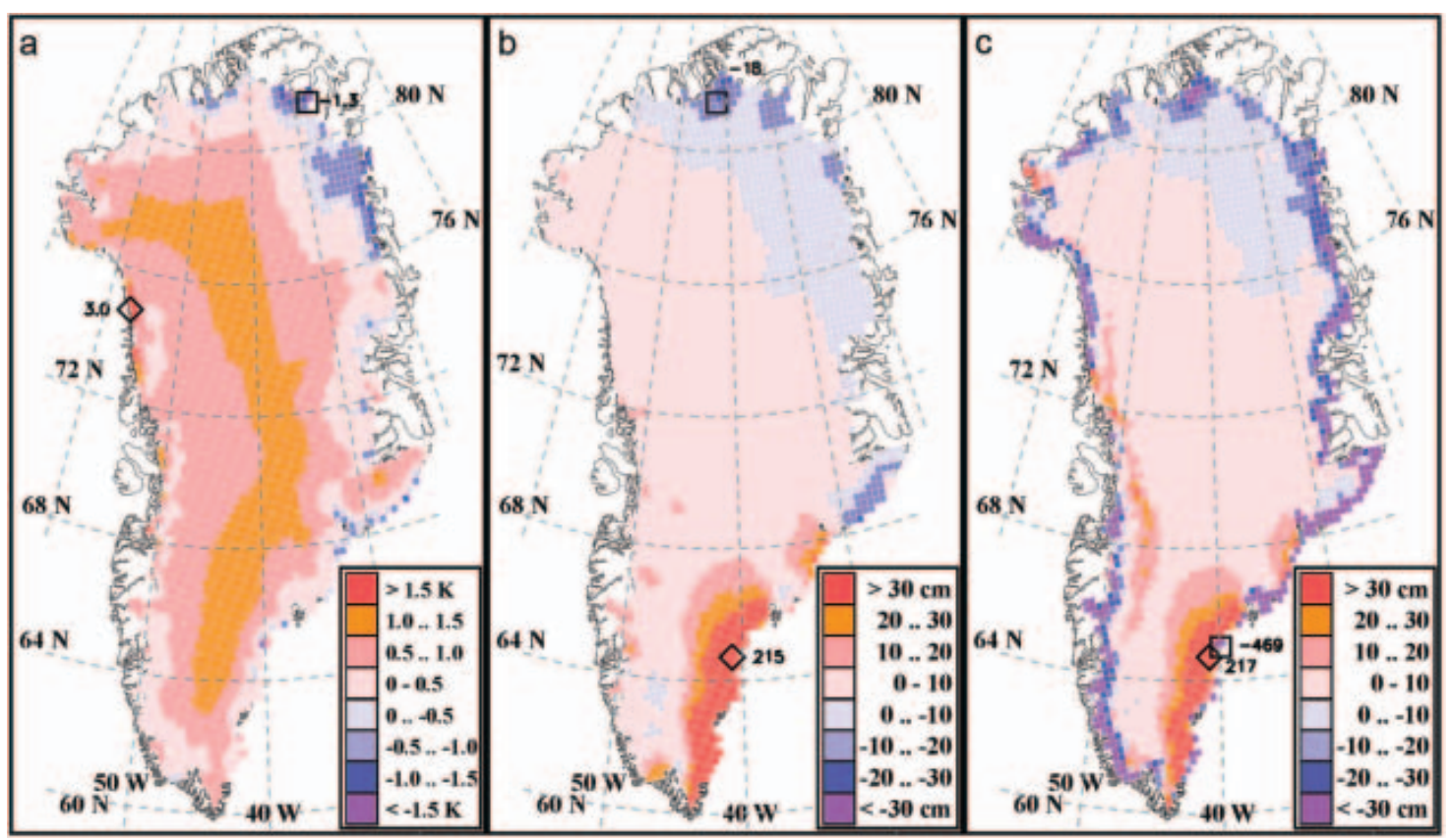

Fig. 2. May-September $2 \mathrm{~m}$ air-temperature change (a), annual solid and liquid precipitation change (cm w.e.) (b) and change in surface mass balance (cm w.e.) (c) over the 1991-2003 period. Minima (squares) and maxima (diamonds) are indicated.

global warming. Here, however, a small negative surface mass-balance trend suggests that increased melting has dominated increased accumulation. Therefore, the ablation zone is simulated to have become wider, as suggested by overall positive trends in equilibrium-line altitude (ELA) over this period (Fig. 3). The peripheral thinning observed by repeat laser altimetry (Krabill and others, 2000) can be at least partially attributed to the warming trends. A decrease in ELA in the southeast is caused by increases in precipitation. Only in the northeast does precipitation appear to dominate the surface mass balance, owing to decreases in both temperature and precipitation.

\section{NORTH ATLANTIC OSCILLATION}

The NAO represents a dominant mode of regional atmospheric variability around Greenland (e.g. Rogers, 1997) and is gauged here as the pressure difference in $\mathrm{hPa}$ between Stykkishólmur, Iceland, minus Ponta Delgada, Azores. During negative NAO, relatively low pressure in the vicinity of southeast and southwest Greenland leads to a shift in the location of the Icelandic low (to the southwest), with more mesoscale lows in the Davis Strait region, causing wind

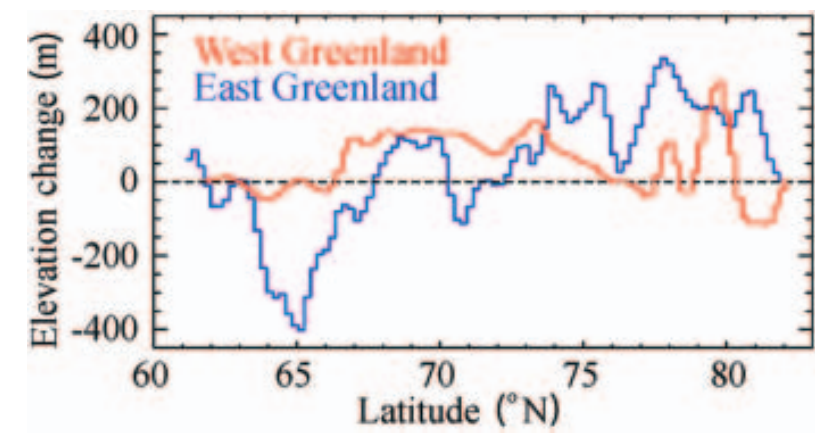

Fig. 3. Change in ELA based on 1991-2003 trends. direction changes that favor (southerly) warm air advection along the southwest coast and over the southern part of the ice sheet. Therefore, the NAO and southern Greenland temperatures are anticorrelated. Temperature sensitivity to the NAO over the ice sheet, as measured by the linear regression slope, is greatest for the southern part of the ice sheet, particularly in winter, with sensitivities up to $-0.9 \mathrm{~K} \mathrm{hPa}^{-1}$ (Fig. 4, top row). Two standard deviations of the NAO fluctuations over the last three decades correspond to $\pm 3.9 \mathrm{hPa}$ in winter, implying roughly a $\pm 3.5 \mathrm{~K}$ winter thermal sensitivity to the NAO. Spring and summer NAO sensitivities imply thermal sensitivities of $\pm 2 \mathrm{~K}$ and $\pm 1 \mathrm{~K}$, respectively. Relevant to ablation is that the NAO explains $40 \%$ of the summer temperature variability along the west coast.

Modeled precipitation variability also contains significant links with the NAO (Fig. 4, bottom row). Consistent with the regional temperature sensitivity, positive NAO, i.e. cold Greenland, is associated with less precipitation, in the southeast by as much as $-11 \mathrm{~cm}$ w.e. $\mathrm{hPa}^{-1}$ in winter, when precipitation magnitudes and fluctuations are greatest. Up to $50 \%$ of the winter precipitation variability is explained by the NAO at locations adjacent to dominant storm centers. A belt of significant NAO precipitation sensitivity traverses the ice sheet from southeast to northwest in winter and autumn and has been identified in an ice-core accumulation record (Appenzeller and others, 1998). Significant positive correlations with the NAO are evident in the northwest in summer, consistent with maximum precipitation there delivered in summer (Steffen and Box, 2001).

\section{CONCLUSIONS}

Results from a 13 year simulation (1991-2003) from the Polar MM5 RCM reveal coherent spatial and temporal variability patterns in temperature, precipitation and surface mass balance over the Greenland ice sheet. Spatially, temperature variability is concentrated along the western slope of the ice sheet, while precipitation variability exhibits 


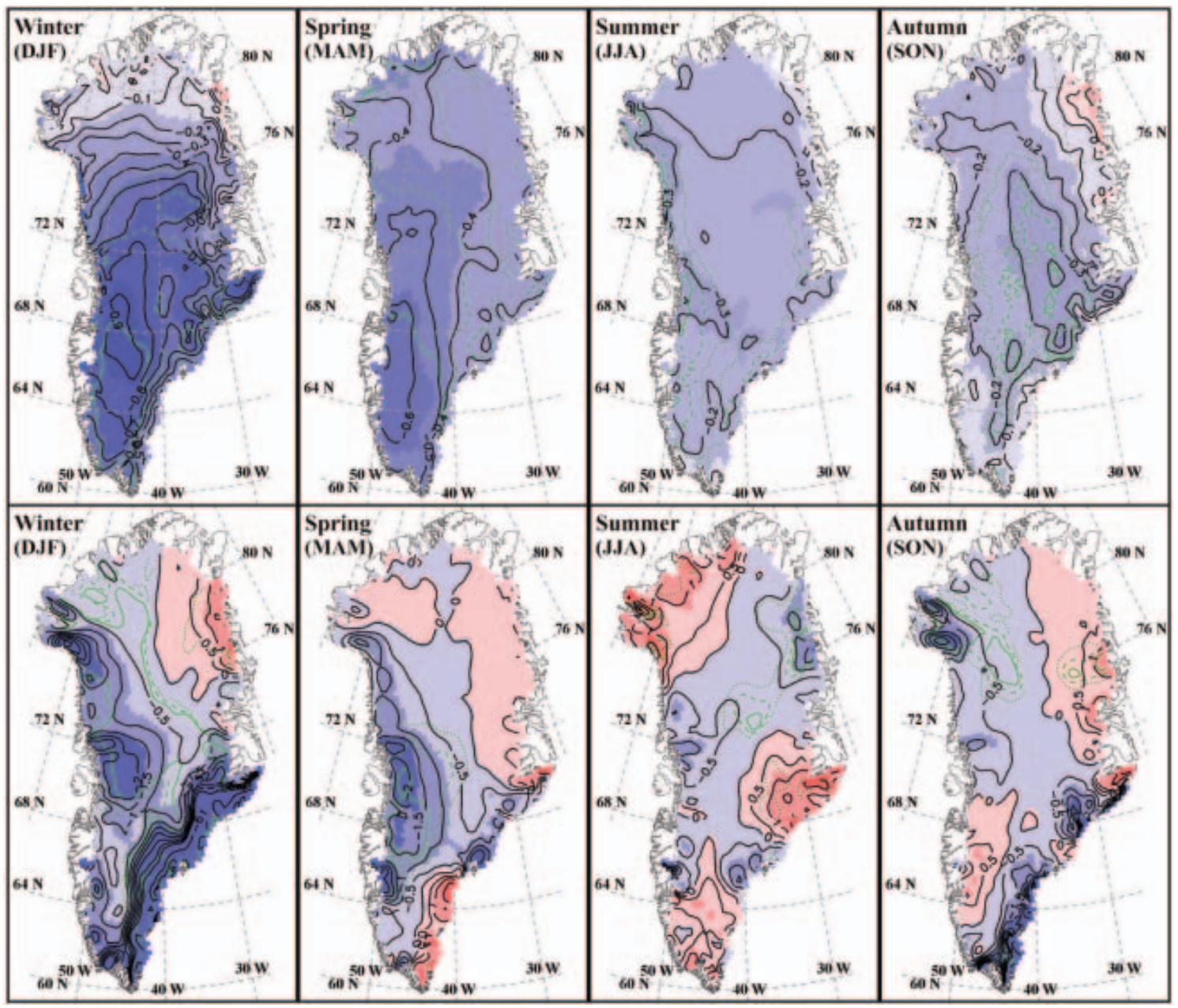

Fig. 4. Greenland ice sheet seasonal temperature (top row) and precipitation (bottom row) sensitivity to the NAO. Statistical significance is indicated by green contour lines: dotted: $>80 \%$; dashed: $>90 \%$; solid: $>95 \%$. Statistical significance was measured as 1 minus the probability statistic $p$. NAO data were obtained from the Internet (c/o J. Rogers, http://polarmet.mps.ohio-state.edu/). Temperature sensitivity isolines are each $0.1 \mathrm{KhPa}^{-1}$. Precipitation isolines are each $0.5 \mathrm{~cm}$ w.e. $\mathrm{hPa}^{-1}$ less than $\pm 4 \mathrm{~cm} \mathrm{hPa}^{-1}$, beyond which they are each $2 \mathrm{~cm}$ w.e. $\mathrm{hPa}^{-1}$.

a more complex pattern that is related to the influence of topography on prevailing storm tracks. Up to half of the summer temperature variability is explained by the NAO, with largest NAO sensitivity in winter. Significant NAO links with precipitation are evident in regions dominated by regional storm centers, i.e. adjacent to the Icelandic and Baffin Bay lows. Temperature and precipitation trends over this period were positive over much of the ice sheet. The Pinatubo volcanic cooling enhances the apparent warming trend when only the decade of the 1990s is considered, the eruption having occurred in the early 1990s. Precipitation trends have the same spatial pattern and sign as temperature, suggesting an association of precipitation and temperature variability. An increase in ELA around much of the ice sheet and a consequent expansion of the ablation zone is evident in the model results. While increasing temperatures lead to an increase in the duration of the melt period and an increase in meltwater runoff, increases in precipitation mostly offset the negative perturbation in total ice-sheet surface mass balance. We may expect an increasing dynamic response of the ice sheet to this period of apparent warming and steepening of the ice-sheet balance profile, especially given that meltwater increases appear to accelerate ice-sheet velocities (Zwally and others, 2002).

\section{ACKNOWLEDGEMENTS}

This work was supported by NASA grants NAG5-12407 and NAG5-11749. Thanks to A. Ahlstrøm, D. Dahl-Jensen and an anonymous reviewer for comments on the manuscript. This is Byrd Polar Research Center contribution 1307.

\section{REFERENCES}

Abdalati, W. and K. Steffen. 1997. The apparent effects of the Mt. Pinatubo eruption on the Greenland ice sheet melt extent. Geophys. Res. Lett., 24(14), 1795-1797.

Appenzeller, C., T.F. Stocker and M. Anklin. 1998. North Atlantic Oscillation dynamics recorded in Greenland ice cores. Science, 282(5388), 446-449.

Box, J.E. 2002. Survey of Greenland instrumental temperature records: 1873-2001. Int. J. Climatol., 22(15), 1829-1847.

Box, J.E. and A. Rinke. 2003. Evaluation of Greenland Ice Sheet surface climate in the HIRHAM regional climate model using Automatic Weather Station data. J. Climate, 16(9), 1302-1319.

Box, J.E., D.H. Bromwich and L.-S. Bai. 2004. Greenland ice sheet surface mass balance for 1991-2000: application of Polar MM5 mesoscale model and in-situ data. J. Geophys. Res., 109(D16), D16105. (10.1029/2003JD004451.) 
Bromwich, D.H. and 6 others. 2001a. Mesoscale modeling of katabatic winds over Greenland with the Polar MMS. Mon. Weather Rev., 129(9), 2290-2309.

Bromwich, D.H., Q.S. Chen, L.S. Bai, E.N. Cassano and Y. Li. 2001b. Modeled precipitation variability over the Greenland ice sheet. J. Geophys. Res., 106(D24), 33,891-33,908.

Cappelen, J. 2003. World Weather Records 1991-2000 - Denmark, The Faroe Islands and Greenland. DMI Tech. Rep. 03-34.

Cappelen, J., B.V. Jørgensen, E.V. Laursen, L.S. Stannius and R.S. Thomsen. 2001. The observed climate of Greenland, 1958-99 with climatological standard normals, 1961-90. DMI Tech. Rep. 00-18.

Cassano, J.J., J.E. Box, D.H. Bromwich, L. Li and K. Steffen. 2001. Evaluation of Polar MM5 simulations of Greenland's atmospheric circulation. J. Geophys. Res., 106(D24), 33,86733,889 .

Dyurgerov, M. and J. Dwyer. 2001. The steepening of glacier mass balance gradients with Northern Hemisphere warming. Z. Gletscherkd. Glazialgeol., 36, 107-117.

Greuell, W., B. Denby, R.S.W. van de Wal and J. Oerlemans. 2001. Correspondence. 10 years of mass-balance measurements along a transect near Kangerlussuaq, central West Greenland. J. Glaciol., 47(156), 157-158.

Hanna, E., P. Huybrechts and T.L. Mote. 2002. Surface mass balance of the Greenland ice sheet from climate-analysis data and accumulation/runoff models. Ann. Glaciol., 35, 67-72.
Krabill, W. and 9 others. 2000. Greenland Ice Sheet: high-elevation balance and peripheral thinning. Science, 289(5478), 428-430.

Li, L. 2003. Greenland's influence on cyclone activity. (PhD thesis, The Ohio State University.)

McConnell, J.R. and 6 others. 2001. Annual net snow accumulation over southern Greenland from 1975 to 1998. J. Geophys. Res., 106(D24), 33,827-33,838.

Ohmura, A., P. Calanca, M. Wild and M. Anklin. 1999. Precipitation, accumulation and mass balance of Greenland ice sheet. Z. Gletscherkd. Glazialgeol., 35(1), 1-20.

Rogers, J.C. 1997. North Atlantic storm track variability and its association to the north Atlantic oscillation and climate variability of northern Europe. J. Climate, 10(7), 1635-1647.

Steffen, K. and J. Box. 2001. Surface climatology of the Greenland ice sheet: Greenland Climate Network 1995-1999. J. Geophys. Res., 106(D24), 33,951-33,964.

Van der Veen, C.J. 2002. Polar ice sheets and global sea level: how well can we predict the future? Global Planet. Change, 32, 165-194.

Wild, M., P. Calanca, S.C. Scherrer and A. Ohmura. 2003. Effects of polar ice sheets on global sea level in high-resolution greenhouse scenarios. J. Geophys. Res., 108(D5), 4165. (10.1029/ 2002JD002451.)

Zwally, H.J., W. Abdalati, T. Herring, K. Larson, J. Saba and K. Steffen. 2002. Surface melt-induced acceleration of Greenland ice-sheet flow. Science, 297(5579), 218-222. 